\title{
AUBERT DE LA RÜE: \\ Viajante Em Observação
}

Mabe Bethônico

Escola de Belas Artes da UFMG

\section{RESUMO}

Edgard Aubert De La Rüe (1901-1991) era geógrafo, geólogo, fotógrafo suíço, cujo arquivo, depositado no Musée d'Ethnographie de Genève, é fonte de pesquisa para a construção de uma biografia em projeto de arte e pesquisa iniciado em 2012. Fontes documentais juntamente à sua obra científica servem de fundamento para produção literária e visual, especulando sobre vida, obra e métodos do autor. De La Rüe esteve no Brasil, seu trabalho sobre o sertão nordestino é foco deste artigo, em que se experimenta observar seus interesses e compará-lo a personagem ficcional através de seus meios arquivísticos e impulso enciclopédico.

Palavras Chave

Arquivo, fotografia, geografia humana, ficção.

\begin{abstract}
Edgard Aubert De La Rüe (1901-1991) was a Swiss geographer, geologist and photographer. His archive, deposited at the Musée d'Ethnographie de Genève, is a research source to a biographical construction in an artistic research project began in September 2012. Documental sources, together with his scientific works are used as fundament to a literary and visual production, especulating about life, work and methods of the author. De La Rüe was in Brazil, his work about the North-east and its sertão is the focus of this article, where we experiment to observe his interests and compare him to a fictional character through his archivist means and encyclopaedic impulses.
\end{abstract}

Key words

Archive, photography, human geography, fiction. 
Desde que iniciei a construção do projeto "O Colecionador", uma coleção de imagens de jornal em processo desde 1996, trabalho a partir de arquivos e acervos. "O Colecionador" é um arquivo de imagens, classificadas através de uma estrutura de conteúdo (Figura 1). O trabalho apresenta um personagem através de sua coleção, disposta parcialmente em vitrines e disponibilizada para consulta. "O Colecionador" i circula em exposições desde 2000 e a visibilidade deste trabalho, que é do âmbito ficcional, literário e artístico, gerou propostas para intervenções em museus e coleções de diferentes origens, a partir de seus acervos e arquivos, geralmente a convite de instituições e curadores de arte.

Através de pesquisas, que resultaram em publicações, exposições e eventos (nos contextos de suas produções compreendidos como "obras"), trabalhei no Arquivo Wanda Svevo da Fundação Bienal de São Paulo para duas edições da Bienal, em 2006 e 2008, na Biblioteca do MAM SP, no Acervo do Museu de Arte da Pampulha, no arquivo do Kunstverein de Munique, na Biblioteca do Museu de Antioquia e no Museu de Mineralogia Tulio Ospina, ambos em Medellín, dentre outros.

Em 2009, a convite do MIS-SP [Museu da Imagem e do Som de São Paulo], desenvolvi um trabalho em seu arquivo fotográfico que resultou na produção de dois vídeos e um artigo crítico, em colaboração com o artista e curador de fotografia suíço, Joerg Bader, diretor do Centro de Fotografia de Genebra. Um dos filmes, Juparassu [2010, 16'], é construído com fotografias do acervo e um conto do escritor mineiro Murilo Rubião. Como conseqüência dessa experiência, elaboramos um projeto a ser construído a partir de acervo fotográfico suíço e uma produção literária suíça. Um acesso especial ao arquivo de fotografia do Museu de Etnografia de Genebra [MEG] em 2011 possibilitou delinearmos uma produção em diálogo com um conto do escritor suíço Robert Walser.

Nessa concessão especial de acesso, sendo o local restrito à pesquisa interna da curadoria e pesquisadores do Museu, foi-nos apresentada a coleção Edgar Aubert De La Rüe. O trabalho em audiovisual está em fase de digitalização de imagens e em processo. Mas a coleção revelou-se de grande interesse por razões expostas a seguir, instigando uma investigação sobre seu conteúdo de forma ampla 
e sobre o personagem fotógrafo que a constituiu. Trata-se de arquivo inédito, tanto a coleção de fotografias quanto o fundo de documentos do autor, ambos pertencentes ao MEG.

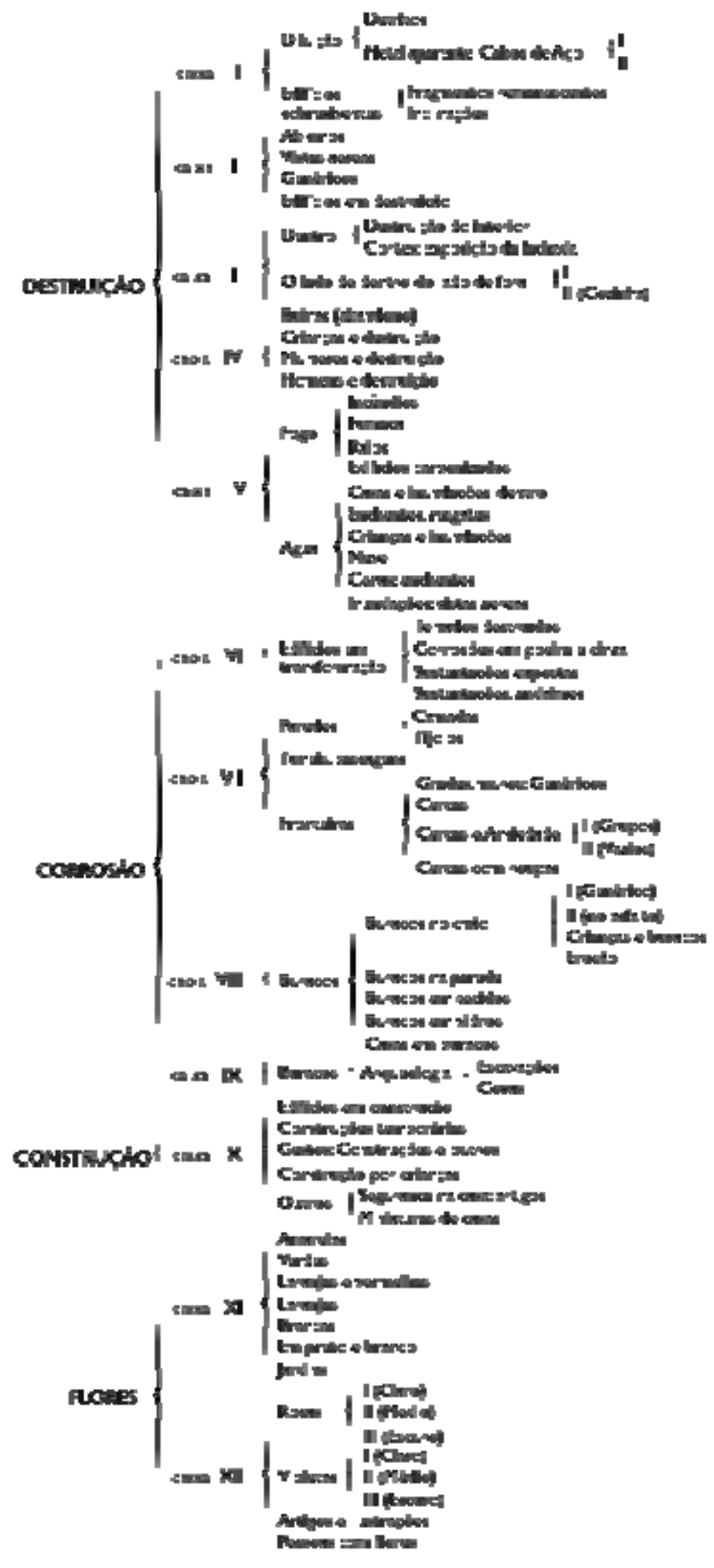


Edgar Aubert De La Rüe era geógrafo, geólogo, viajante e fotógrafo, o que é uma peculiaridade, sendo que a grande maioria dos cientistas de sua época e mesmo mais tarde, não produzia imagens fotográficas de qualidade. Essa produção de imagens geralmente não possuía autonomia, estando a serviço dos estudos teóricos. Nascido em Genebra em 1901, De La Rüe morreu em Lausanne em 1991; se consagrou devido a pesquisas geológicas em terras remotas (Saint-Pierre-et-

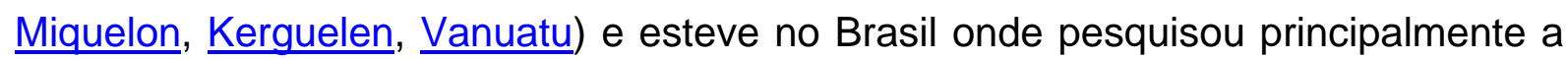
caatinga e a Amazônia, tendo ainda reportado sobre diversas outras regiões brasileiras.

O fundo Edgar Aubert De La Rüe de fotografia pertencente ao MEG é composto por diferentes suportes fotográficos, que vão de slides de vidro a películas positivas de diferentes formatos, séries de cópias em papel que parecem ter sido produzidas pelo próprio autor, álbuns com ampliações em cor e negativos de formatos e materiais diferentes com e sem cópias correspondentes. Através desse acervo é possível traçar o desenvolvimento das mídias fotográficas ao longo do século 20.

De grande interesse são suas classificações e organização das imagens, criteriosamente dispostas em caixas, nomeadas sob temas compilados ao longo de toda sua vida. Por exemplo, De La Rüe registrava mercados de rua, enquanto percorria o mundo em estudos geológicos. As fotografias feitas ao longo do tempo recaíam em álbum específico sobre o assunto, e ali encontram-se imagens de épocas e países distintos em suportes variados. (Figuras 2, 3 e 4) Outros temas foram colecionados amplamente e observados por onde fosse, como a série de "cercas", contendo construções em pedra, cercas vivas com inúmeras espécies de plantas, trançados de diferentes materiais como madeira, fibras e bambus, muros de pau-a-pique e tijolos, cercas de metal e telas, retirados de regiões remotas tanto quanto de seu próprio em torno na Suíça.

Conjuntos temáticos trazem em pastas fotografias originais que ilustram os livros de sua autoria. Um volume organiza vegetações peculiares reproduzidas em artigo para revista científica. Ao mesmo tempo encontramos fotografias pessoais, retratos do autor e sua mulher, em viagens e em casa, onde se pode ver uma vitrine 
de sua coleção particular de pedras ornamentais. Como De La Rüe tinha uma segunda casa na região de Valais, encontramos fotografias aéreas do Alpes Valaisianos e cristais da região, bem como paisagens idílicas de seus vales em cores, no verão e sob a neve, numa estética próxima à de calendários, demonstrando ainda seu interesse por espécies de plantas e modos específicos de construção na topografia alpina. Percebemos seus estudos geológicos em imagens de pedreiras, rochas e paisagem de modo geral, registradas mesmo enquanto estava em lazer nos Alpes; fotografa sua própria casa coberta de neve, ou um arcoíris visível por detrás da casa do vizinho.

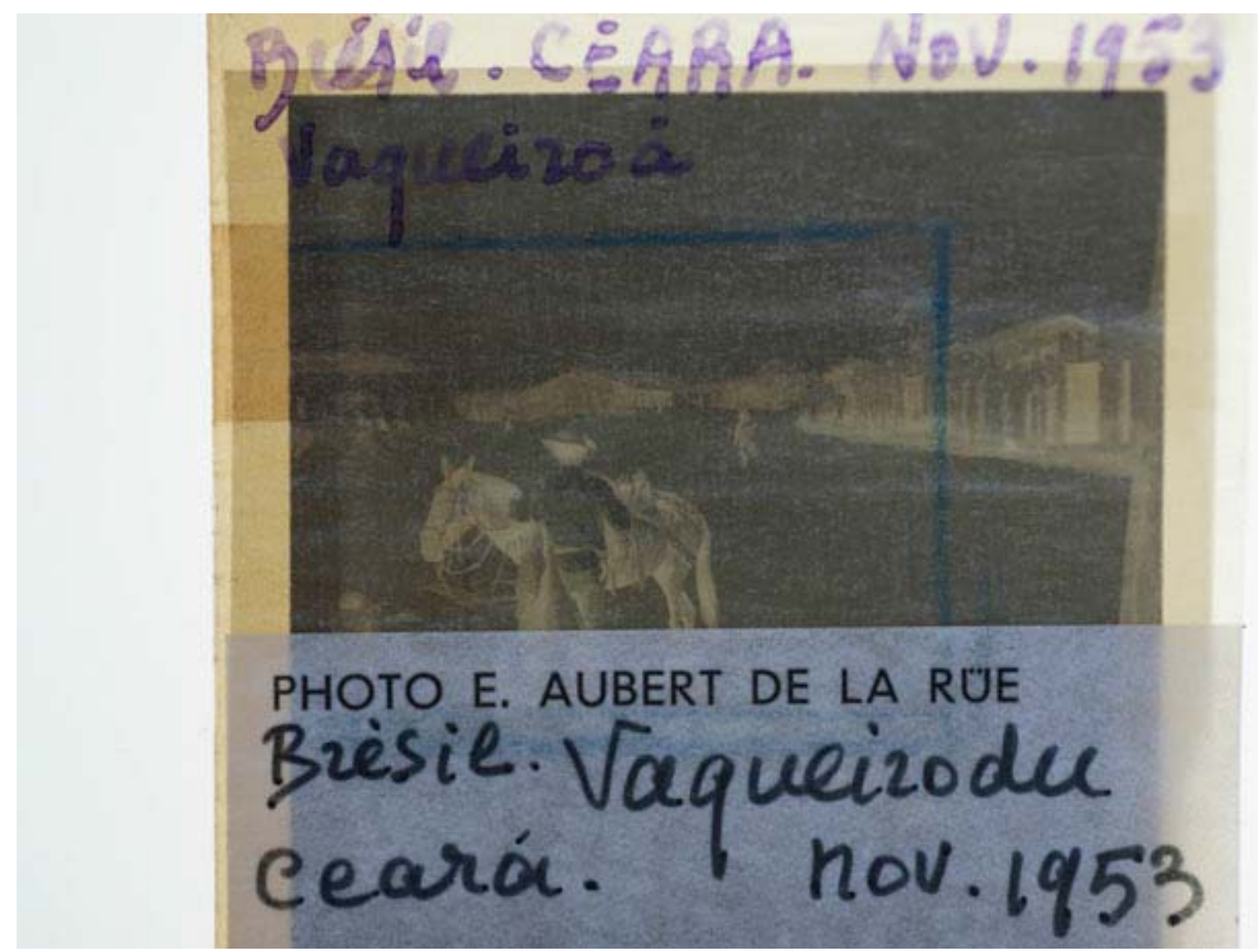



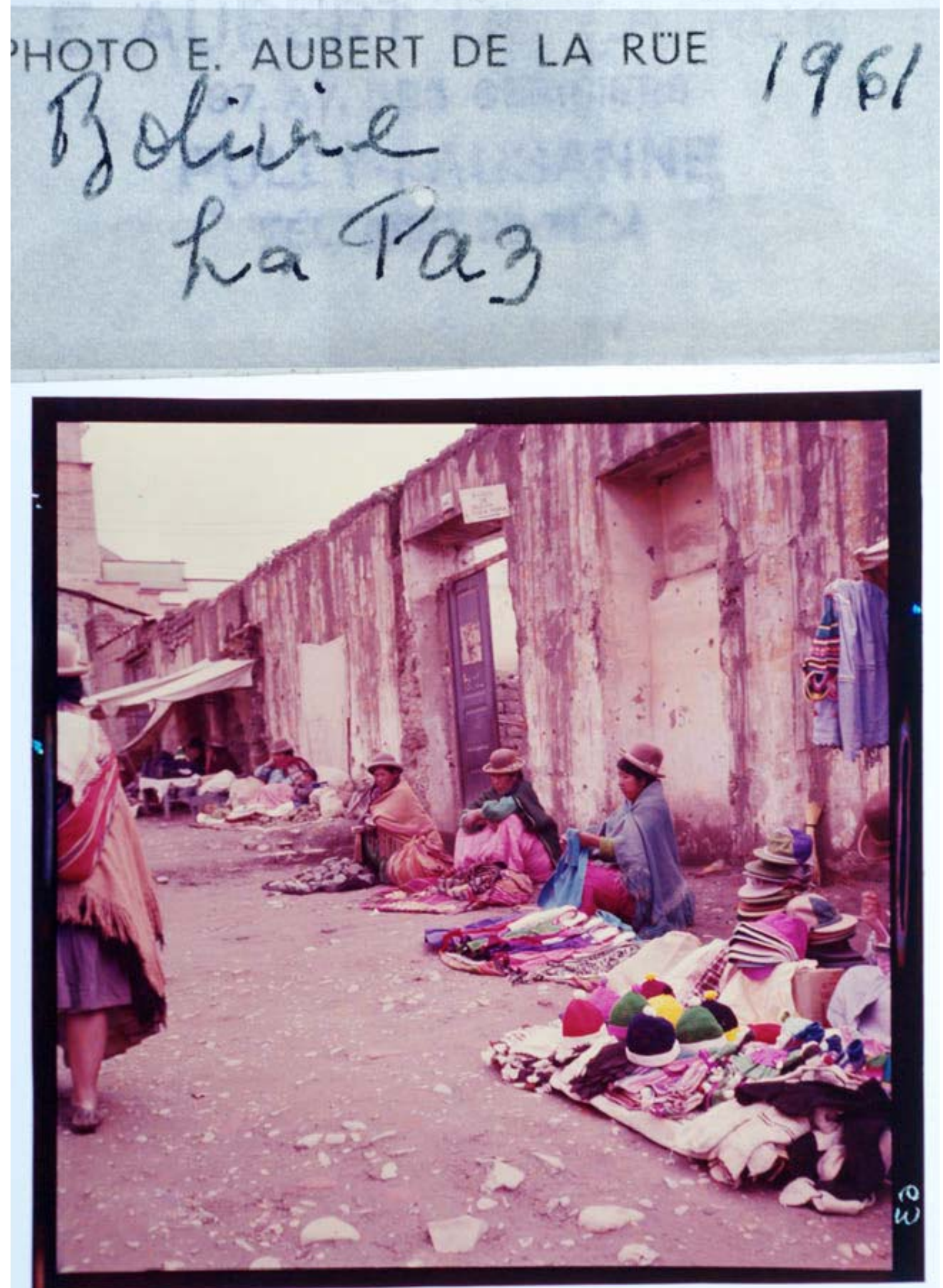

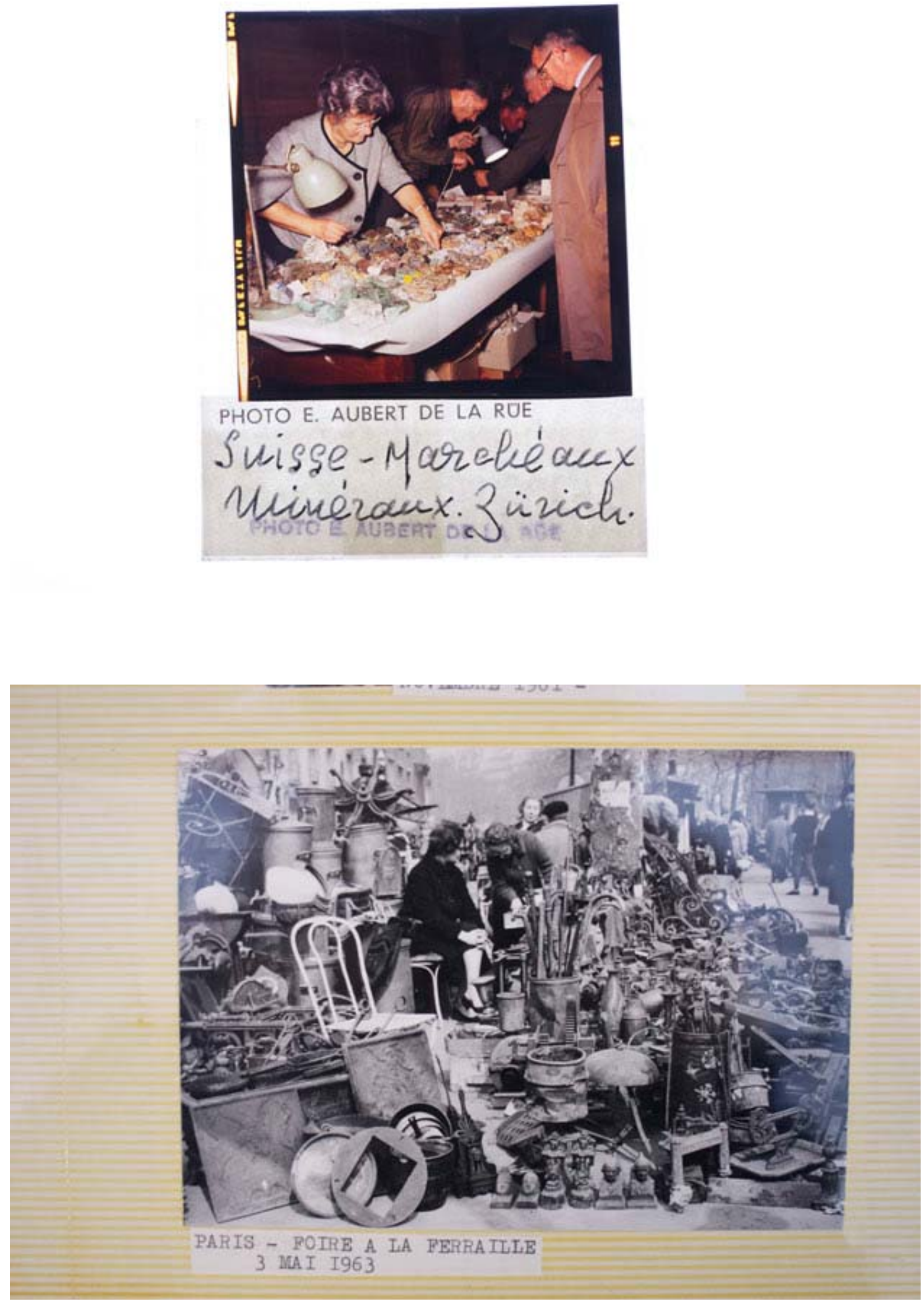


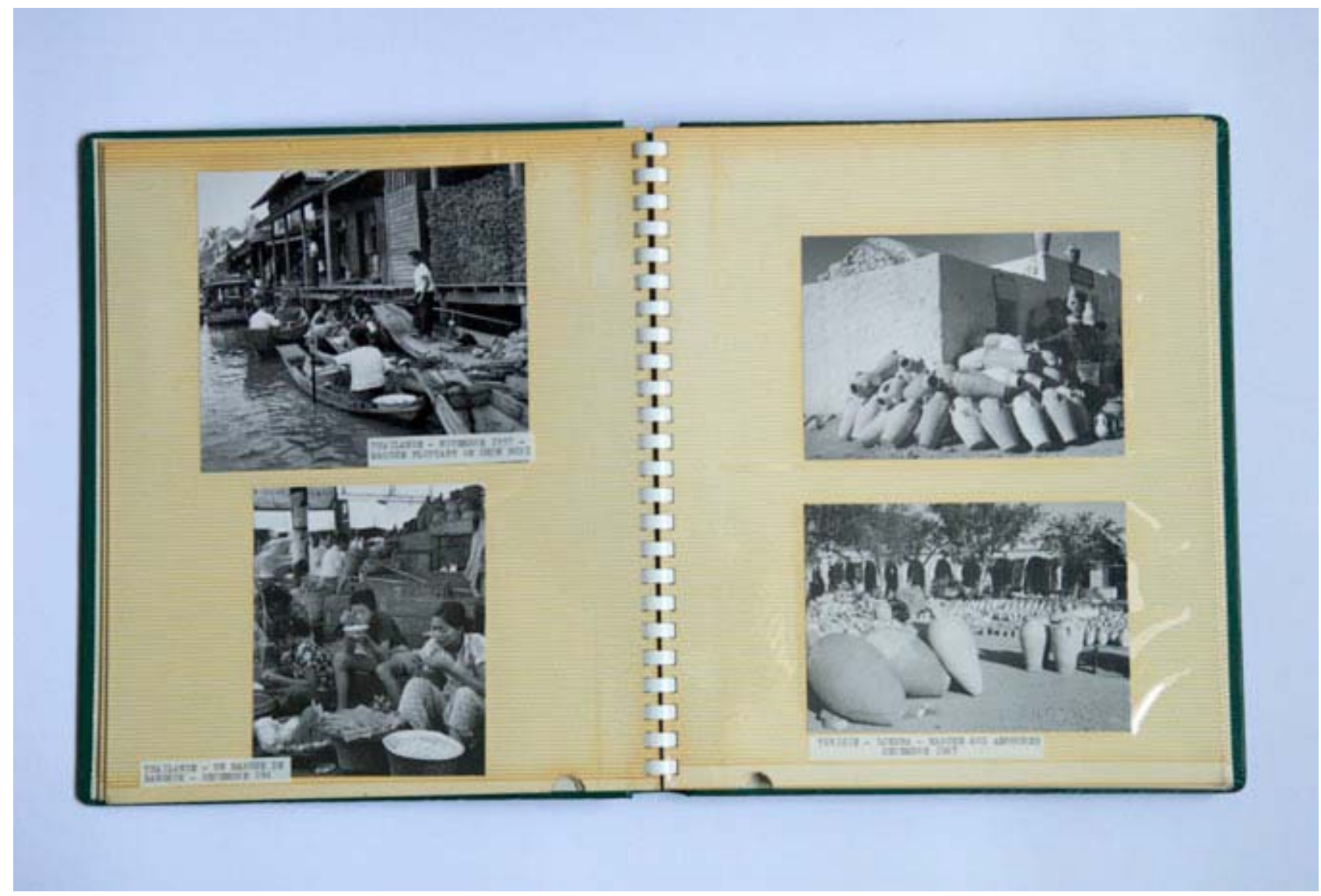

As fotografias da coleção têm naturezas diferentes; legendas escritas à mão com comentários e indicações diferenciam os tipos de imagem. As imagens comentadas são feitas em geral para acompanhar relatos científicos sobre suas viagens por diferentes lugares do mundo. Todo o material traz seu carimbo (PHOTO - E. AUBERT DE LA RÜE) algumas vezes indicando seu endereço em PullyLausanne e geralmente mencionando o local fotografado.

As imagens do autor revelam um sujeito que particularmente estuda os territórios e como se comportam os homens em cada contexto, - sob o vento, falta e excesso de água, baixas e altas temperaturas e altitudes, etc. Nos livros "O Homem e os ventos", "O Homem e os vulcões", "O homem e o mar", "O homem e as ilhas", os assuntos se organizam em extensivas classificações, buscando cercar cada elemento abordado com múltiplas perspectivas de comportamento, tanto humano, quanto espacial-geográfico. Por essa razão seu trabalho fotográfico, entre a geografia e a etnografia, encontra-se depositado no MEG. 


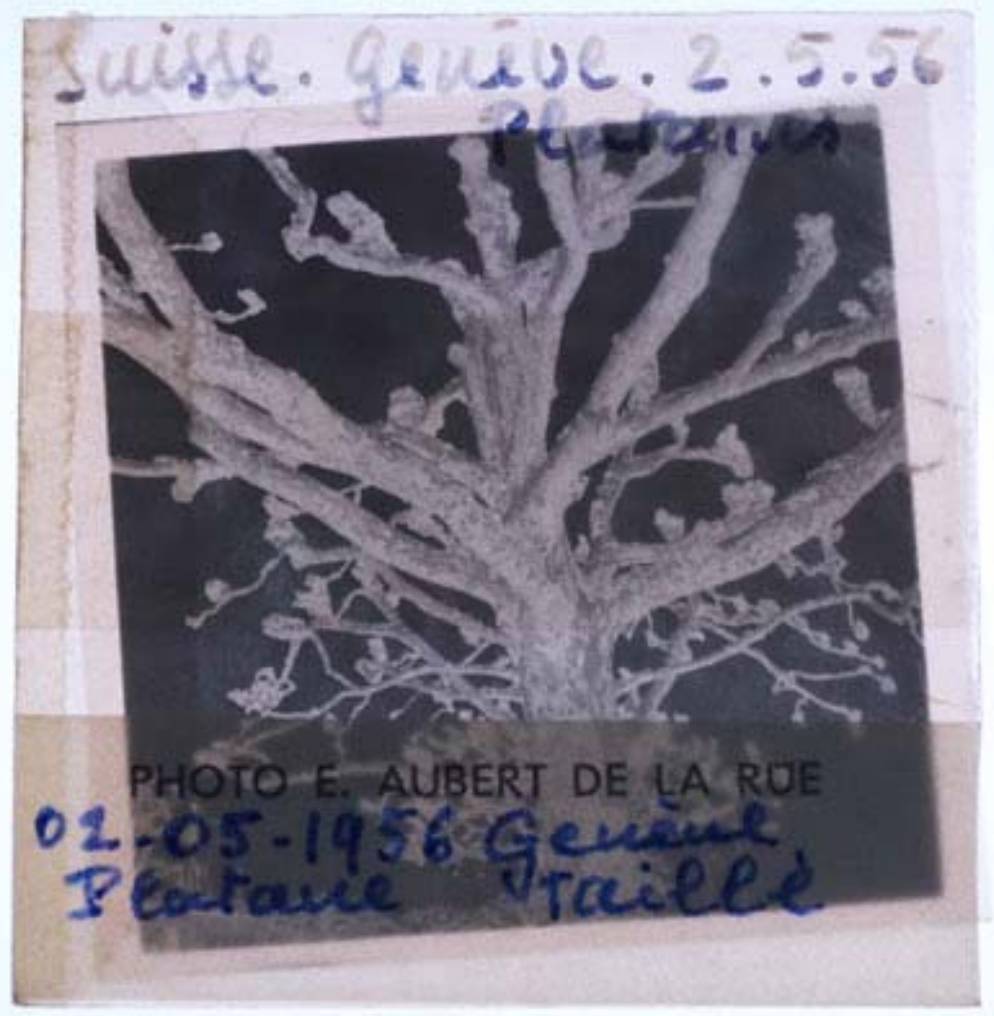

Em "O homem e os ventos" são observados, em diferentes regiões do globo, as denominações das correntes de ar nos oceanos, suas influências em terra e formas de proteção contra seus efeitos, os perigos que pode causar e a importância de seu estudo para as conquistas das navegações portuguesas. De la Rue aborda com cuidado os moinhos de vento, como são construídos e para que servem em vários continentes; o vento como inimigo e como aliado dos homens, a tecnologia em torno de seu estudo e a aviação. Aparentemente, é o primeiro livro escrito sobre como os ventos afetam os homens, abordando quase todas as esferas das atividades humanas, agricultura, sociologia, construções e cidades, engenharia, biologia, medicina, viagens, esportes, seu interesse fundamental para a meteorologia e para o geógrafo. A obra é acessível, dinâmica e enciclopédica em sua abordagem. $\mathrm{O}$ autor não deixa de mencionar o lugar dos ventos na literatura e na representação visual em cartografia, e como afetou o curso da história humana, demonstrando critério, paixão e imaginação. Apresentamos ao final do artigo uma estrutura organizando graficamente os conteúdos indexados nessa obra junto aos 
subtítulos de capítulos, confiando ser um modo de apreensão de sua abordagem sobre o vento, em que considera eventos atmosféricos, tecnologia e comportamento.

Neste momento o Museu de Etnografia de Genebra se encontra fechado para exposições até 2014, devido a reforma e extensão de seu edifício. Trata-se de momento importante da história do Museu, em transição para sua reabertura, com renovações das mostras permanentes, implementação de dinâmicas de mediação e publicações. O MEG foi fundado em 1901 por Eugène Pittard (1867-1962), também fundador da cadeira de antropologia da Universidade de Genebra. Se inicia com coleções do Museu de arqueologia, parte do Museu de Arte e de História, -o principal museu de Genebra e também objetos advindos de outras coleções. Em 1921 o MEG possuía 8.000 objetos; hoje conserva 80.000 objetos e mais de 300.000 documentos dos cinco continentes, sendo o segundo maior Museu de Etnografia da Suíça depois do Museu de Etnografia de Basel, um dos mais importantes da Europa.

Em experiências em espaços museológicos e a partir de documentos, o foco das minhas ações tem sido elaborar sobre a própria instituição; os trabalhos são mediações entre o conteúdo estudado e a própria estrutura que o preserva e divulga. Aubert De La Rüe e o Museu de Etnografia de Genebra são ambos nascidos em 1901. Este pode ser um pretexto para a construção de uma linha do tempo em que se relacionam procedimentos de coleção e catalogação, em nível pessoal-autoral e público-institucional.

É notável a ausência de uma biografia sobre o autor, identificável em pesquisas iniciais, em bibliografia e internet. Sua obra é também apenas listada parcialmente, não sendo encontrada em nenhuma referência uma compilação que cita sua produção científica de modo completo. Significativamente, Aubert de La Rue é o nome de uma montanha de gelo na Antártica, primeiramente identificada por ele.

Ela é descrita em mais de um website como tendo sido "descoberta por um geólogo francês (sic) e batizada com seu próprio nome, em 1929".

Propus ao MEG a construção de uma biografia visando a edição de um audiovisual, a partir dos arquivos, sua obra científica e pesquisa de campo. Diante do conhecimento sobre algumas de suas obras publicadas, e o acervo documental de correspondências e fotografias referentes às suas pesquisas, seria possível 
traçar sobre o personagem e configurar um perfil, uma biografia? Seria de interesse essa biografia especulativa do autor, que se remete a documentos sobretudo fotográficos e se insere no campo ficcional/ literário? ...e não seria esse campo inerente a toda e qualquer biografia?

A obra de Aubert De La Rüe teve relevância em sua área científica e ele usa ao mesmo tempo uma linguagem poética, ao descrever paisagens e suas ocupações, os contextos de vida das pessoas no lugar. De sua relação com o Brasil, derivam duas obras: Brésil aride. La vie dans la Caatinga (Paris, 1957) e Tropiques La nature tropicale, (co-autor, Paris, 1954). Em diversas outras publicações o país está presente em estudos de caso. De La Rüe esteve no Nordeste, em missão técnica geológica, mas sua leitura extrapola a funcionalidade do propósito inicial, e ele considera uma amplitude de condições e aspectos da geografia humana. A Vida na Caatinga é resultado de estudo sobre recursos naturais e resulta num compêndio de anotações botânicas e urbanas, sobre o território social tanto quanto o indivíduo, sobre a paisagem, a comida e fatos históricos lendários. Por um lado, traz informações e dados de relevância técnica e curiosidades e sabor anedótico. - Uma escrita minuciosa de viagem pela paisagem através do relevo, sem deixar de observar também com astúcia o contexto de vida sobre o lugar.

As imagens do autor que ilustram o volume são fotografias de espécies de plantas, vistas das cidades, diferentes mercados de rua (uma disposição de potes de cerâmica, uma cena de baús que transportam mercadorias, uma cena com venda de frutas, outra com pilhas de gaiolas com pássaros, venda de adereços indígenas e rapadura) um grupo de garimpeiros, duas cenas de formações rochosas, a secagem de fumo de rolo, uma capela, jangadas, a distribuição de leite no lombo de burro, carros de boi, um vaqueiro a cavalo, um sertanejo e um vaqueiro. (FIGURA 8) Apenas essa lista descritiva das imagens constantes no livro dá um panorama sobre seu amplo interesse de observação sobre os lugares estudados. 

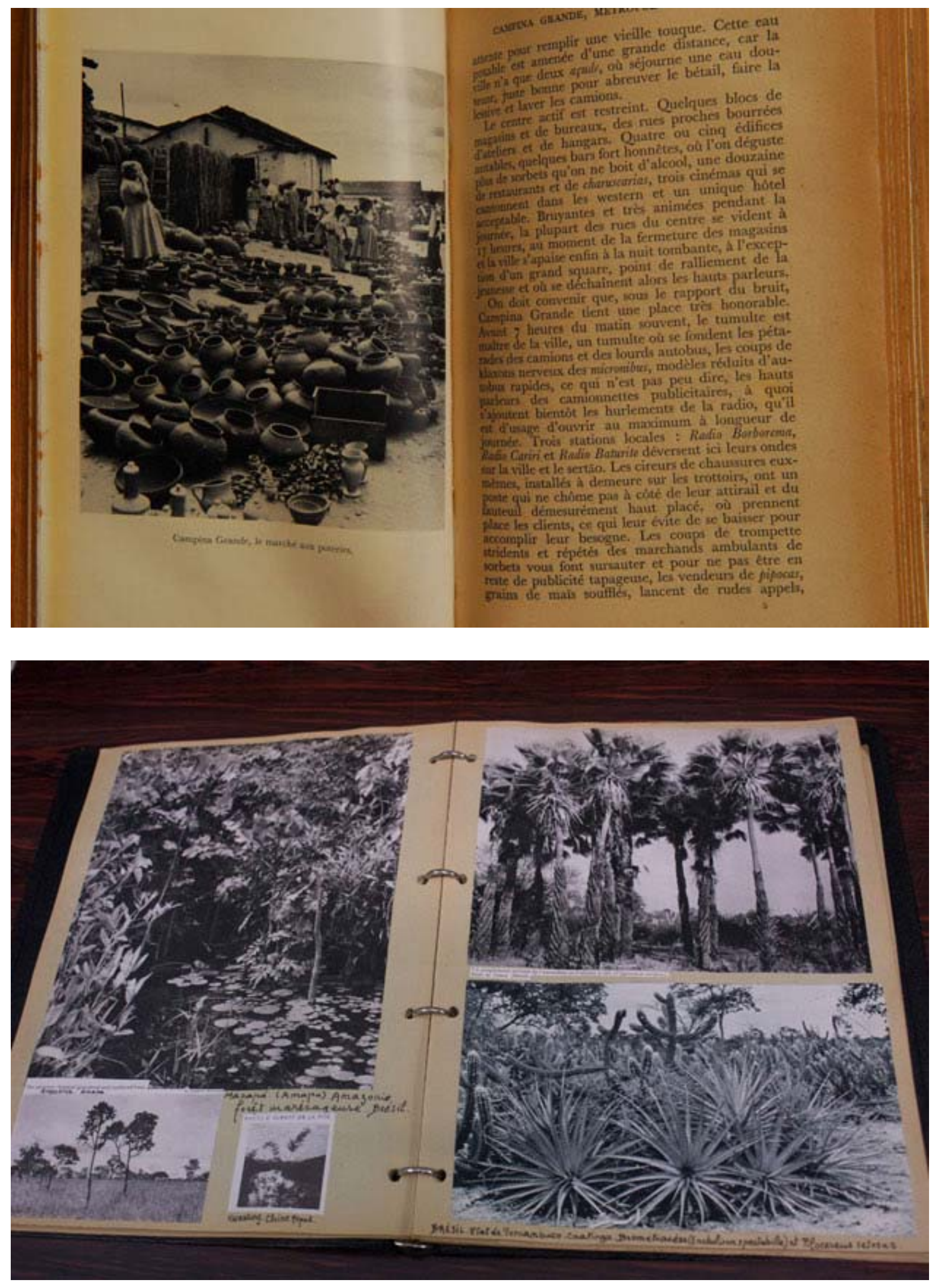
O foco das minhas pesquisas é a obra Brasil Árido ( $A$ vida na caatinga). Ela se organiza nos seguintes capítulos: Apresentação - Introdução ao Polígono da Seca - O Nordestino - Recife, Enganadora Porta de Entrada do Nordeste Campina Grande, Metrópole do Sertão - Primeiros Contatos com o Rio Grande do Norte - Visita aos Garimpeiros - A Miragem do Ouro - Cidades, Paisagens e Cenas do Litoral - Viagem a Serra Grande - No Coração do Ceará - O Sertão de Pernambuco - Passeio ao Redor do São Francisco - Alto Sertão da Paraíba - Na Época do Inverno. Ao final, há um "Índex de termos brasileiros citados".

Reproduzo a seguir os termos do índex constantes ao final do livro com suas grafias originais, com algumas observações e transcrições. É possível perceber, através dos termos citados pelo autor, sua percepção sobre hábitos e personagens do sertão, tanto quanto seus lugares e plantas, ainda que ele mencione e se desculpe por sua pesquisa ter sido uma incursão curta em poucos meses, através de um território tão vasto e complexo.

Açude - Agreste - Águas - Alto - Angico* - Aracati - Arueira* - Avelois* - Babaçu* Bananada - Barriguda* - Bicho - Boqueirão - Borracha d'agua - Brejo - Caatinga Caatingueiro - Cabeça de frade* - Caboclo - Cachaça - Cacimba - Cafesinho Cajaca de couro - Caju* - Cajueiro* - Cajuína - Caldeirão - Caldo de canha Canaviais - Cangaceiro - Carioca - Cariri - Carnauba* - Carnaubais - Carne de sol Caroa* - Castanha de Cajú* - Catavento - Catolé* - Cearense - Chapada - Charruto Churrascaria - Chuvas de Cajú - Cidade - Coco verde - Coqueirais - Coronel Craubeira* - Curimatau - Doce - Doutor - Engenho - Faca - Facada - Favela Fazenda - Fazendeiro - Faveleiro* - Fecheiro* - Feijoada - Feirante - Flagellado Fogão - Fumo - Fumo em rolo - Fumo bravo - Garimpagem - Garimpeiro - Gibão Goyabada - Guarapa - Invierno - Jagunço - Jangada - Jangadeiro - Jurema* Ladeira - Macambira* - Macahyba* - Malacacheta - Mandacaru* - Manteiga de fazenda - Maracujá* - Mata - Mataburro - Mixto - Neblina - Nordestino - Oiticica* Olho d'agua - Palma* - Palmatoria* - Palmita* - Parapeito - Paus de Arara - Pinha* Pinhão bravo* - Planalto - Rapadura - Rasto de boi - Retirantes - Rocado - Seca Seringais - Sertanejo - Sertão - Sitio - Tanque - Umbuzeiro* - Vaqueiro - Várzea 
Vasante - Vatapa - Veiero - Ventos gerais - Veraniste - Verão - Vila - Voçoroca Xique-Xique* - Zona da Mata.

*espécies de plantas e frutos, descritos em sua forma ou função e em alguns casos citados os nomes científicos. (Figura 9)

Termos relacionados a personagens nordestinos:

Caatingueiro

Caboclo

Cangaceiro

Doutor

Flagellado

Garimpeiro

Jagunço

Retirantes

Sertanejo

Vaqueiro
Habitant de la caatinga

Métis, habitant du sertão.

Nom donné aux anciens bandits du Nord-Est.

Docteur, titre donné à toute personne un peu instruite.

Victime de la sécheresse.

Prospecteur; celui qui exploite un gisement d'une façon primitive.

Sertanejo Révolté lors de la guerre civile de Canudos (Bahia).

Fuyards du Nord-Est en temps de sécheresse.

Habitant du sertão.

Bouvier du Nord-Est.

Como curiosidade, destaco da lista alguns termos relacionados a bichos, para a seguir traduzir a breve introdução que abre o volume Brasil Árido - A Vida na Caatinga, onde o autor descreve as circunstâncias de sua vinda ao Brasil e se pode perceber o tom de toda a obra. 


\section{Cajaca de couro} sa teinte et

\section{Curimatau}

\section{Est.}

Mataburro

de passer.

\section{Introdução}

Nom donné à un passereau brun clair, par analogie entre

celle d'une veste de cuir.

Poisson d'Amazonie introduit dans les réservoirs du NordDispositif installé sur les chemins pour empêcher le bétail

O Brasil tem a dimensão da Europa, mas está longe de ter sua diversidade. As enormes extensões oferecem paisagens pouco variadas, - as de floresta tropical úmida e savana, na maioria dos casos. Os principais relevos, que constituem geralmente grandes formações no sudeste do país, não possuem elevação para determinar mudanças climáticas susceptíveis de alterar significativamente a aparência da vegetação, como é o caso, por exemplo, de toda a América Andina. $O$ fato de se estender do Equador até o interior da zona tropical dá ao Brasil, ao contrário de sua proporção de meio continente, uma homogeneidade muito grande. De modo geral, sua principal produção vegetal (algodão, café e cana-de-açúcar) é a mesma no norte e sul do país, graças à uniformidade do clima. Mas, se de certo modo, a natureza não é muito diversa no vasto domínio do Brasil, há uma região que ocupa lugar à parte, particular, de originalidade própria. Gostaria de dizer do Nordeste, com sua individualidade muito marcada, mas pouco invejável, devido à aridez de seu clima.

O contraste que se pode notar ao percorrer o Brasil está nos homens mais do que nos elementos naturais. Se pode dizer de dois Brasis: há um moderno e pulsante, industrial, empreendedor e muito ativo, e do outro lado, um atrasado, sonolento e provinciano, - e o Nordeste faz parte deste. Do ponto de vista humano, é este Brasil velho, fortemente enraizado no passado, a que pertence a principal parte do Nordeste. 
Sobre o Brasil, ignoramos a existência deste vasto domínio subequatorial, com poucas chuvas, submetido a secas periódicas, ao qual uma certa população está atrelada, com vários milhões de habitantes marcados por uma situação de grande crescimento demográfico. Um solo estéril, desolado pela seca e chuvas devastadoras, incapaz de nutrir adequadamente seus habitantes.

Uma profusão de mitos, ficções e histórias, na realidade marcados por fantasias maravilhosas, familiarizou o público com o mundo amazônico. Mas encontramos muito menos ou nada, especialmente em francês, de histórias dedicadas a esse território, que une vários estados vizinhos da Amazónia, mas completamente diferentes, que é o Brasil árido do Nordeste, com o qual todos brasileiros estão atrelados sentimentalmente. Sua natureza árida e sua população rude, perpetuamente instável, de uma mentalidade atrasada, ocupam um grande lugar na literatura deste país.

Me foi dado o privilégio de estar por vários meses nesse lugar ignorado por demais e viajar por milhares de quilómetros. Isso foi em 1953-1954 na ocasião de uma missão de avaliação que me foi confiada pela Unesco para assistência, numa colaboração técnica com autoridades do Brasil. Mas foi uma viagem curta demais, nesse território maior do que a França e realizada com um fim preciso. A questão era descobrir suas possibilidades minerais, buscando sua valorização para melhoria de sua economia precária e as duras condições de vida que em geral marcam a vida de seus habitantes.

Minhas funções como especialista me colocou em aproximação com os engenheiros do Departamento Nacional de Produção Mineral e houveram numerosos momentos cordiais com os prefeitos dos municípios onde passei grande parte do meu tempo. Também estive com grande número de nordestinos sem títulos oficiais, proprietários de fazendas, exploradores de minerações, caboclos e garimpeiros, sempre solícitos, junto aos quais encontrei frequentemente uma hospitalidade preciosa. Todos me proveram documentação útil sobre seu país, com a qual busquei ver e compreender um pouco de sua alma. 
Não posso esconder que pode parecer superficial a descrição do Nordeste contida nessas páginas, mas acho que pode ser de interesse este descritivo, ainda que sumário, desse território tão particular e distinto do resto do Brasil, marcado pelo pitoresco e cores locais. Essas notas de viagem mostram aspectos curiosos e os contrastes deste Brasil atrasado, com certeza no início da sua industrialização (...). Também veremos a grande variedade de paisagens, algumas de incrível desolação, outras de esterilidade desértica, outras de monotonia infinita, como os imensos platôs que margeiam o curso do São Francisco. Mas também há lugar no Nordeste para cenários alegres e muito verdes, de floração deslumbrante e lugares férteis nas épocas de chuvas abundantes. São com frequência visões efémeras, que se esvaem depois de algumas semanas de sol intenso.

A CAATINGA, através da qual se desenvolve esse itinerário, é uma palavra de origem indígena que designa no Brasil a floresta débil e retorcida, cheia de espinhos e cactos, adornada de vegetação agreste típica do Nordeste árido e desolado. Nesse lugar hostil, à sua própria sorte, sobre o cavalo ágil, está o personagem simbólico, imagem viva do passado, que é o vaqueiro, este cavaleiro da caatinga, em seu chapéu tricórnio de couro de cabra e coberto de sua pitoresca roupa de couro ruço. (DE LA RÜE, 1957, p. 7-9) ii

A obra A Vida na Caatinga contém observações geológicas e econômicas, que foram o propósito de sua missão no Brasil, mas a leitura de De La Rüe sobre as características humanas da população nordestina revela um observador atento a um amplo cenário ao redor, e não somente físico-geográfico, como já indica a introdução da obra. O autor está atento, no curto período de tempo em que esteve naquela região do país, aos diferentes personagens que vivem sobre o território árido do Nordeste, e sobre eles tece um perfil dramático, a respeito de seus modos de vida tanto quanto da realidade em torno. Sem elevar os nordestinos à condição de heróis, tampouco mostrando-os como vítimas, De La Rüe compreende seus fluxos, sua resistência e suas deficiências; descreve seus hábitos e desventuras, sua dieta, seus traços, o atraso da mentalidade e seus esforços contra o calor e as carências.

$\mathrm{Na}$ introdução ao capítulo $\mathrm{O}$ Nordestino, que reproduzo a seguir, se percebe a amplitude do relato que está para se desenvolver ao longo do capítulo. $O$ autor faz 
um retrato breve porém não sem profundidade sobre as questões do habitante nordestino, percorrendo tópicos os mais variados, de sua índole à sua apresentação física, de sua dieta à sua habilidade na agricultura, questões econômicas e culturais.

\section{[Capítulo II] - O Nordestino}

Ainda que hostil, o sertão não é totalmente improdutivo, e seus recursos limitados podem se somar às suas muitas vantagens, fazendo do nordeste uma unidade econômica que não é negligenciável. Açúcar, sal, fibra de agave, cera de carnaúba e minerais são as principais produções dessa região do Brasil.

Bem ou mal, o sertão deveria possibilitar a vida de uma parcela relativa de seus habitantes, e não miseravelmente. Porém, uma grande parte dos nordestinos, marcados pela fome, tem uma existência lamentável. O mal vem de uma população excessiva, prolífica ao extremo, amontoada em espaços ingratos. Alguns dizem, de modo um pouco paradoxal, mas com razão, que no nordeste estéril, somente o homem é fértil. Famílias com 10 ou doze crianças são recorrentes, com 15 crianças não são exceção, e existem famílias que contam 20 ou mais filhos. Durante os últimos 50 anos, a população do Ceará aumentou na proporção de 161\%! Por todo o Brasil, exceto em distritos urbanos, as densidades mais altas se encontram em certos municípios deste estado tão pobre.

É compreendido e constantemente lembrado que o maior problema do nordeste, causa de todos seus males são suas chuvas deficitárias e incertas. O escritor Gilberto Freyre sintetizou um sentimento que é largamente aceito em seu país que diz, justamente, que "a palavra Nordeste nos evoca sempre o espectro das secas". As autoridades gastam somas consideráveis e orientam a maioria de seus esforços para obter água em quantidade suficiente para o povo do sertão. Projetos mais quiméricos tem sido mesmo propostos neste sentido.

Em realidade, o problema essencial é outro, e vozes oficiais tem enfatizado isso. Como disse um alto funcionário brasileiro, Renato Martins, qualificado 
especialmente sobre o assunto, já que ocupa a Divisão de Terras e Colonização: "O problema do Nordeste é essencialmente um problema de despopulação". Mas considerar a diminuição da densidade demográfica de um território superpopulado é uma questão delicada, que pode prejudicar a um número de interesses e mesmo provocar forte oposição. No entanto, a única solução razoável seria começar por evacuar para terras não ocupadas e colonizáveis mais próximas uma parte da população.

O recenseamento de 1950 indicou um total de 12 milhões e meio de habitantes para todo o nordeste. Sua taxa de crescimento é tal que podemos seguramente contar hoje com um milhão a mais. A imprecisão que marca os contornos do Polígono da Seca torna aleatória qualquer estimativa relativa ao sertão propriamente dito. O número de 7 milhões parece próximo da realidade, e um número igual de habitantes se amontoam na estreita costa, superpopulada em sua pequena superfície, por ser o lugar ocupado pela cultura da cana-de-açúcar, que deixa pouco espaço para as culturas de subsistência. Se concordamos com esses números, isso quer dizer nove habitantes por kilômetro quadrado no sertão, que parece a princípio razoável, mas excessivo para quem conhece sua imensidão improdutiva.

Os nordestinos vivendo nos limites do triste polígono não são todavia os únicos. Milhões deles, - todos números precisos seriam ilusórios, mesmo se citamos números de 5 ou 10 milhões - tiveram de deixar o território desde o início do século, se colocando de modo desordenado nos mais diversos estados do país para encontrar melhores condições de vida. A estimativa, feita durante a última seca, de 1951-53 é de que pelo menos 500.000 deles deixaram suas casas. Tem sido mesmo contados um número de 400.000 por ano de êxodos anteriores e metade dessas pessoas retornaram às terras quando a seca chegou ao fim. De todo modo, o número de nômades espalhados por todo o Brasil aumenta constantemente.

O nordestino resulta da fusão de três raças: a indígena, a branca e a negra. Os brancos puros, assim como os negros sem mistura, são hoje em dia pouco numerosos. Exceto por algumas dezenas de sobreviventes em ínfimas reservas da Paraíba e de Pernambuco, os índios puros desapareceram. Seus traços se encontram, todavia, com muita nitidez em certos indivíduos esparsos, com maior frequência em alguns distritos, sobretudo no Ceará. A 
presença, no sertão, de nordestinos loiros com olhos azuis se justifica pelas relações de outrora entre invasores holandeses com as populações litorâneas.

Para essas raças mistas do Nordeste, se dá, com frequência o nome de caboclos, mesmo que originalmente esse nome fosse aplicado unicamente a descendentes de portugueses e índios. A maioria deles tem hoje em dia mais ou menos sangue negro, mas em menor proporção do que no resto do Brasil. De todo modo, os morenos, com uma infinitude de nuances, são hoje dominantes. Notamos, incontestavelmente, bonitos tipos, sobretudo entre os homens, mas constatamos que a mestiçagem entre brancos e negros nem sempre dão aqui resultados felizes. O número de pessoas mestiças é muito elevado e se pode ver muita gente de pele clara mas com cabelos loiros crespos e traços negróides, que dá efeitos lamentáveis. Os preconceitos de raças não tem o mesmo impacto no Brasil do que sabemos haver em outros lugares. Minhas viagens através do Nordeste me mostraram no entanto que eles não são totalmente inexistentes. Elas me mostraram que a gama de cores está ligada fielmente aos graus da escala social. Com pouca exceção, pessoas mais claras ocupam as situações mais elevadas e a mais baixa camada é constituída em sua maioria por pessoas de cor escura. A cor de certa maneira também tem sua importância nos casamentos e os pares se combinam através dessa relação. A natureza dos cabelos interfere igualmente na escolha dos parceiros. Lisos, demonstram ascendência indígena, do que se pode orgulhar, enquanto que os cabelos crespos demonstram origem africana, menos apreciada.

O rude meio do sertão tem marcado profundamente seus habitantes, os sertanejos, outro modo de nomear os nordestinos do interior. Estes se distinguem por numerosos traços de caráter em relação ao resto do Brasil. De penetração fácil, o Nordeste esteve entre as primeiras regiões colonizadas, mas apesar de tudo, a mentalidade de muitos dos seus habitantes pouco evoluiu ao longo dos séculos. Viajar através desta terra não somente é uma travessia por um território muito particular, de caráter próprio, mas se faz igualmente uma incursão ao passado. Muitos dos fatos que podem surpreender, alguns chocantes, outros em desuso mas encantadores, são remanescentes de outrora. Não somente a mentalidade evolui lentamente, mas o progresso material chega igualmente do mesmo modo. 
O nordestino não deixa de ter qualidades. Não se pode negar que de modo geral, ele é honesto, corajoso, sóbrio, humilde e pacífico. Ele pratica gentilmente as leis da hospitalidade. O habitante do sertão é trabalhador, mais do que o nordestino do litoral. Para ele, trabalho é um obrigação imposta pela difíceis condições de vida. Contudo, os sertanejos são maus agricultores, e devastam involuntariamente seu país com seus métodos de trabalho inconsequentes.

Reconhecemos que o nordestino possui qualidades suficientes para que se diga francamente algumas palavras sobre suas deficiências, relacionadas em grande parte a seu modo de vida. Ele é, ocasionalmente, cruel e vingativo, de amor próprio exageradamente aguçado, que facilmente se arma de uma faca. Basta passar os olhos nos jornais de Recife, Natal e Fortaleza para se surpreender com o número de crimes cometidos diariamente, até 6 em 24 horas, observei uma vez, apenas na capital do Ceará. Os fatos relatados pela imprensa demonstram que os assassinatos não são o triste privilégio dos grandes centros, o sertão os conhece do mesmo modo. As rivalidades políticas, vinganças, histórias de mulheres, muitas vezes com ajuda de cachaça, consequências de discussões advindas de motivos fúteis, são as causas principais. Não se morre frequentemente de morte natural nas terras da caatinga, e um golpe de punhal na barriga, a medonha facada, é um motivo muito recorrente.

A religiosidade mal definida do sertanejo é cheia de contradições e de aberrações estranhas. Ele é supersticioso e seu fanatismo religioso, pode fazer dele um alvo fácil para certos líderes illuminados, o que muitas vezes levou no passado a atos sangrentos e ao banditismo.

Em vista das condições difíceis, impostas por uma natureza severa e hostil, o Nordeste demonstra, como vimos, um crescimento demográfico extremamente elevado. Esse crescimento rápido da população não é infelizmente acompanhado de crescimento dos recursos alimentícios. Para muitos, os recursos são insuficientes mesmo nos anos de chuvas normais. Os procedimentos arcaicos de cultivo, de modo algum adequados à natureza do sol e ao clima, são responsáveis. Eles incendeiam a caatinga e plantam nos declives, de modo que quando chegam as primeiras chuvas fortes 
retirando grandes quantidades de terra, o cultivo se perde. Durante as secas, o rendimento das colheitas resulta simplesmente deficitário.

Existe muita discussão sobre o regime alimentar do sertanejo. Alguns, incluindo Josué de Castro, grande especialista dessas questões, encontra a situação satisfatória em anos normais, e superior ao que se poderia esperar em clima tão desfavorável. Esse regime básico seria suficiente para afastar carências endêmicas de toda natureza e manter o nordestino em boa forma e cheio de energia. Seguindo este ponto de vista otimista, o nordestino viveria até mesmo em abundância em anos de chuvas fartas. Outros, ao contrário, condenam o regime, o qual consideram insuficiente e insípido, pouco conforme os princípios de uma dieta sensata, preocupada especialmente com dosagens equilibradas de vitaminas, sais minerais, proteínas e calorias.

Essa controvérsia se deve às próprias condições do sertão, independente dos caprichos do clima e da irregularidade das chuvas. Não se fala aqui dos fazendeiros ricos, uma minoria ínfima, e falamos apenas da grande massa de sertanejos. Eles são dois tipos distintos.

Uma importante minoria é composta por pessoas de espírito sedentário, firmemente atreladas à terra, trabalhadores, criando alguns animais e cultivando pequenos pedaços de terra. Pouco importa se são efetivamente proprietários, o que é raro, ou onde se situa seu sítio; como é muito frequentemente o caso, no domínio de uma fazenda. No Nordeste, de fato, terra, é desde há muito tempo, dividida em grandes propriedades. Se por acaso há proximidade a uma região de mineração, pode-se alcançar uma vida equilibrada entre agricultor e garimpeiro, o que é ainda melhor. Eles vivem modestamente mas de todo modo convenientemente, de forma não muito diferente do que a maioria das famílias abastadas, ricas de terras mas desprovidas de dinheiro, sem poder mais do que o indispensável, e retirando o pouco essencial de sua propriedade. Esses nordestinos energéticos e robustos, magros mas musculosos, em seu pequeno sítio, geralmente limpo e bem cuidado, são os melhores tipos do sertão. Eles enfrentam as secas sem muito problema. Não são como aqueles que se vê nas estradas abatidos e em farrapos, cheios de crianças e prontos para gastar suas pequenas economias por um êxodo incerto, que arriscam cair em miséria nas grandes cidades, mais lamentável do que aquela do sertão. 
Outra categoria de nordestinos são aqueles menos valentes, sem sorte e instáveis, que não tem muito a perder e que fogem ao menor alerta de seca. Mesmo em anos realmente chuvosos, a fome os atinge. É essa parcela miserável da população que forma o grosso dos retirantes, os fugitivos, que tendem a se aglomerar mais e mais em torno dos pequenos centros, apertados em alojamentos sórdidos, ignorando qualquer noção de higiene, mas onde assistência pode ser mais facilmente obtida, sendo a mendicância mais cômoda.

Queremos ter uma ideia geral de como os sertanejos se alimentam? Milho, feijão roxo, abóbora, farinha de mandioca e batatas doces são a base de sua alimentação, com a famosa carne do sol, carne de boi seca através de sua exposição por vários dias ao sol, tudo completado pelo café, nem sempre de primeira, e grande consumo de rapadura, açúcar bruto de cana, vendido em barras escuras. Eles consomem também leite de seu gado, não muito, por que a produção leiteira é fraca, uma vaca não produzindo mais do que quatro litros de leite por dia. Os mais favorecidos adicionam à lista arroz, ovos, manteiga (manteiga de fazenda), feita artesanalmente e muito líquida, queijo de sertão, branco e sem gosto, e até mesmo cozido não pode ser mantido por muito tempo, mel, um pouco de peixe seco ou salgado, e muito ocasionalmente, bacalhau importado, sobretudo na Páscoa. O uso do pão é quase inexistente nos sítios e nas fazendas, onde é substituído por farinha de mandioca, da qual se encontra sempre um vidro cheio em toda mesa, e que se mistura com todos os pratos. Pão é preparado apenas nas cidades pequenas, para os restaurantes sobretudo, onde é servido de acordo com o gosto, o pão francês, carioca ou o pão doce.

Em regra geral, legumes crus não são o caso para o nordestino, pelo menos não para aqueles do interior, por que os do litoral tem evidentemente maior abastecimento de frutas variadas. Nos principais mercados se pode encontrar, todavia, cebolas, muitos tomates, duros e sem gosto, pepinos bastante insípidos, melancias, e eventualmente um melão honesto. Os cocos verdes para beber são muito apreciados em todo o sertão e pequenas 'cocoterias' existem até mesmo nas mais distantes cidades do interior. Com a polpa são preparados doces, que modificam um pouco da eterna goiabada, servida como sobremesa, manhã e noite, todos os dias do ano em todos os 
hotéis do Brasil. Com a polpa do coco se preparam excelentes sorvetes, especialidade do Nordeste. (DE LA RÜE, 1957, p. 28-35) iii

Seria possível considerar este livro dentro da tradição de livros de viagem. Seu testemunho é minucioso e aprofundado nos detalhes, demonstrando sua percepção ampliada e consequente no conteúdo científico. Enquanto se apresenta sob um espectro literário se mostra como estudo ordenado, aparentemente sem a rigidez da linguagem técnica, mas uma exposição rigorosa.

Aubert De La Rüe pode ser comparado ao personagem O Colecionador aqui já mencionado, que percorre os jornais, dali retirando as imagens que irão constituir suas questões. Na obra publicada de De La Rüe e nas primeiras pesquisas no acervo do MEG percebe-se sua pulsão classificatória, que lidera os percursos orgânicos de sua escrita. A organização já mencionada, presente no arquivo fotográfico, é indicativa de seu método colecionista e está refletida no estudo sobre a caatinga e em "O Homem e os Ventos", por exemplo. O autor demonstra fôlego em seu acúmulo sistemático, e cuidado na aproximação ao objeto de estudo, sujeito ao espaço e ao tempo, enquanto aborda o contexto com afastamento crítico. Isso caracteriza o estudo minucioso de seus temas, aos quais os registros fotográficos produzidos nas investigações de campo adicionam, apesar de sua autonomia e interesse próprios. Diante da amplitude dos temas (o nordeste brasileiro, os ventos, os vulcões, o mar, etc.), textos e imagens formam compêndios voltados à observação do ser humano, - o habitante em diferentes regiões do planeta, sendo que para isso a paisagem é pretexto e referência.

O contato com a produção deste autor possibilita transitar entre questões amplas como a geografia e turismo, botânica, geologia e etnografia. Essa multiplicidade de assuntos me permite como artista pesquisadora articular, com o pretexto de uma biografia, uma construção poética em meio a paisagem e sua ocupação. O espaço na multiplicidade de percursos registrados por De La Rüe possibilita vagar, investigar e distrair por mundos, tempos, temáticas. Apesar do foco desta pesquisa ser sobre o Brasil, uma caixa de slides pode conter palmeiras brasileiras junto àquelas de muitos outros países. Tipos físicos brasileiros são 
guardados junto a tipos japoneses, equatorianos, bolivianos, africanos, portugueses. O contexto dos assuntos são muitos, lugares vizinhos e distantes do Brasil, se encontram em semelhanças e diferenças. Dentre os interesses de De La Rüe estão os mercados de rua; ele captou cenas de mercados ao longo de sua carreira como cientista viajante por mais de 40 anos. Organizada em caixas próprias no arquivo, essa coleção traz um panorama da vida humana no mundo sobre os passeios de ruas e em bancas, mercados urbanos e suburbanos, venda de produção caseira, artesanatos, animais, vendidos em barcos nos rios, em lombo de animal, sobre asfalto, ruas de terra e praças. Índia, Brasil, Suíça, Irlanda, Portugal, Grécia, Espanha, França, Finlândia, Polinésia, Tailândia, Chile, Bolívia, Suécia se encontram em uma única caixa de transparências em formato $6 \times 6 \mathrm{~cm}$, produzidos ao longo de mais de 30 anos de viagem.

Não encontramos nada escrito por Aubert De La Rüe relacionado a estes mercados dentre os seus documentos ou suas coleções de recortes de jornal e estudos. Este silêncio nos leva a especular sobre a significância dos mercados para o autor. Seria uma relação de mera curiosidade e contemplação? Geólogo, fotógrafo, 'explorador'? Ele tinha uma curiosidade turística e distante que o impelia a registrar estes lugares?

Você é exótico, outro, estrangeiro, estranho. Meu dinheiro compra seus três dinheiros, e você ainda quase me doa, uma barganha. Você faz lindamente, por que você tem tempo. Meu tempo é curto, o seu é barato, e o que você faz dá trabalho. Seu produto é diferente, você aqui em pé, vendendo, eu assisto. Estou aqui para olhar, você se mostra para sobreviver, eu viajo para conhecer. Você apresenta, eu observo, eu julgo, você serve, eu compro, eu exploro, eu te registro, você me observa. Quando retornar eu leciono, eu publico, eu critico, anuncio, ensino, eu ganho, sou pago - para te assistir e te apresentar, te ficcionalizar, analisar quem você é. Eu pesquiso, você faz, planta. Você é meu produto e eu te invento, - já que não te conheço. Eu viajo, você permanece, eu transito, você se fixa. ${ }^{1}$

\footnotetext{
${ }^{1}$ Extrato de apresentação audiovisual sobre o autor, performado pela autora em maio de 2013 no Museu de Arte de Tel Aviv, no evento Embodied Archaelogy of Architecture and Landscape, organizado por Ana Paula Cohen.
} 
De La Rue não observa o 'mercado' de modo amplo: mercado negro, negócios, pirataria, a troca, o dinheiro. Ele não escreve sobre exploração, dominação, escravidão, prostituição. Ele traz material para o Museu de Etnografia de Genebra e de Paris e para sua coleção particular. Ele paga o investimento dos governos em suas viagens trazendo objetos exóticos adquiridos a baixo preço, que irão, fora de seu contexto, figurar por sua beleza e pelo que representam de árduo trabalho. Mas etnografia pode se desvincular da implicação de discussão de valor? De La Rüe não publicou sobre o assunto dos mercados, presente extensivamente apenas no acervo de suas fotografias, mas a herança de tal material pelo Museu de Etnografia de Genebra pode ser potencialmente 'explorada' em seu programa. 


\section{Voulez-vous me r}

dresser à vous à propos d'un sujet que vous ond: la sécheresse et la famine dans le Nou ai lu d'ailleurs avec un grand intérêt vots nant cette région).

Voici ce qui en est: -- Depuis assez lon tention de vous demander s'il serait poss: - de vous un article sur la calamité ci-des - la "Revue pour l'étude des Calamités". E s venons de constater que, pour compléter réparation, il nous manque la matière néc t remplir une dizaine de pages.

Je suis certain qu'une description sur 1 ord-Est du Brésil -- description faite pa a voyagé dans cette région -- aurait un g i les lecteurs de notre revue.

Dans l'espoir de recevoir une réponse af ous prie de bien vouoir agréer, cher Mons sion de mes sentiments les meillewrs.

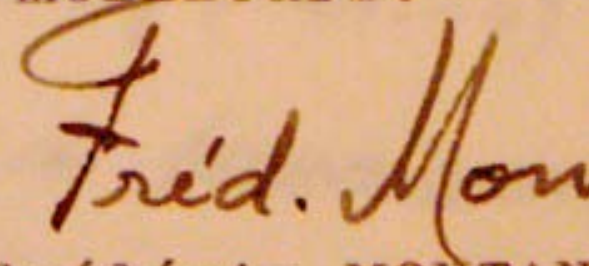

Frédéric MONTAN conseiller technique à I'Uni d membre du bureau de la sociét 
Alguns anos após sua viagem ao Brasil e a publicação do livro La Vie dans la Caatinga, De La Rüe foi convidado a apresentar sobre a caatinga numa publicação internacional sobre catástrofes. (imagem) Ainda que tenhamos conhecimento sobre a permanente crise social, econômica e climática dessa região, 'catástrofe' denota um desastre de proporção considerável, ou um fracasso com fim desastroso. Em geologia, pode ser um cataclisma, um acontecimento violento. Uma questão que deriva deste documento é se o Brasil nos anos 50 lidava com o nordeste com a emergência ou alerta necessários. Até que ponto o Polígono da Seca não era visto pelos próprios brasileiros como um país distante, exótico? - Um olhar de não pertencimento, semelhante ao do próprio De La Rüe, que no entanto, se reportou com certa acuidade sobre a região, buscando compreender suas implicações em detalhes. Se o livro tivesse à época circulado no Brasil em português ele seria capaz de afetar esta relação distante?

Com apoio do CNPq e do Museu de Etnografia de Genebra, a obra La Vie dans La Caatinga está sendo traduzida numa dinâmica colaborativa junto a diferentes participantes tradutores. A obra em português será expandida com documentos fotográficos inéditos relacionados à viagem do autor ao nordeste, e será publicada no Rio de Janeiro como parte do projeto editorial do Capacete Entretenimentos em Maio de 2014. Além das implicações inerentes ao tema da caatinga presentes na obra, consideramos produzir uma análise sobre a relevância atual desta obra e à época, bem como uma discussão em torno da dinâmica de sua tradução como projeto de arte.

\section{Referências Bibliográficas}

DE LA RÜE, Edgar A. Brésil Aride (La vie dans la caatinga). Librairie Gallimard, Paris, 1957.

Man and the Winds. Trad. Madge E. Thompson. Hutchinson's, Londres, 1955. 
'Disponível em http://www.ufmq.br/museumuseu/colecionador

ii Tradução M.B., com contribuições de Joerg Bader.

iii Tradução M.B., com contribuiç̃̃es de Joerg Bader.
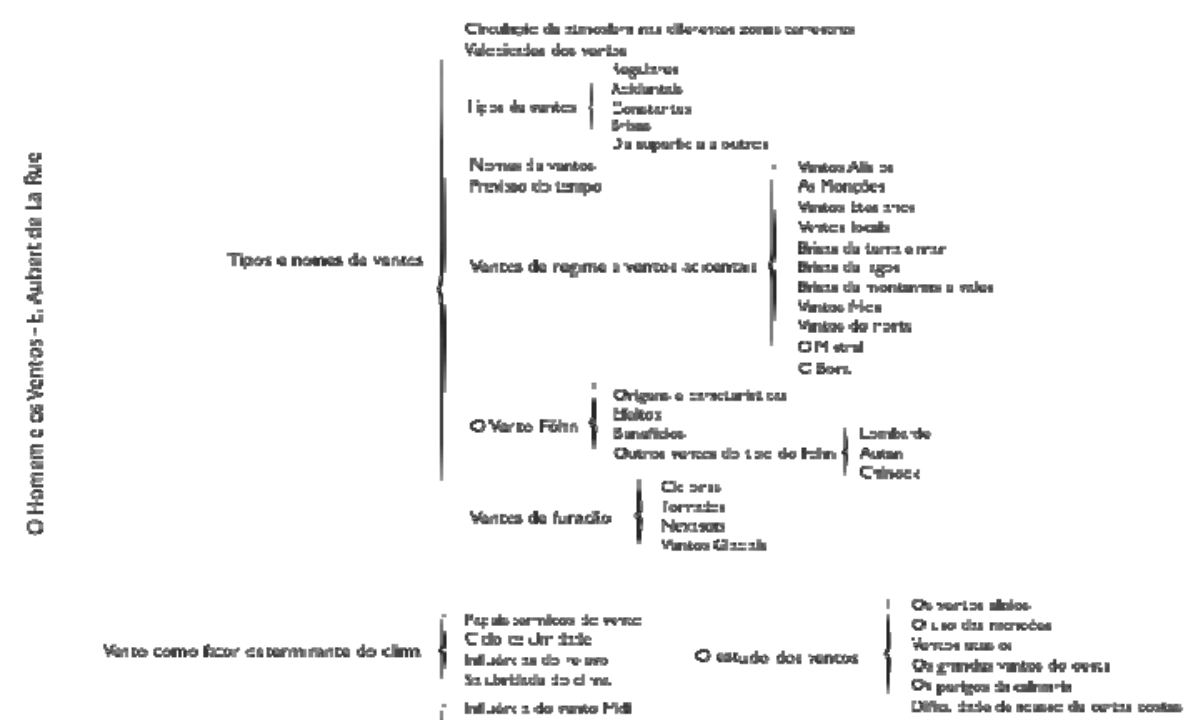

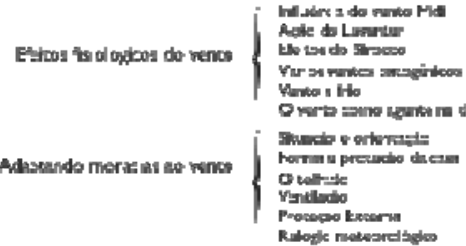

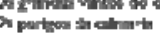

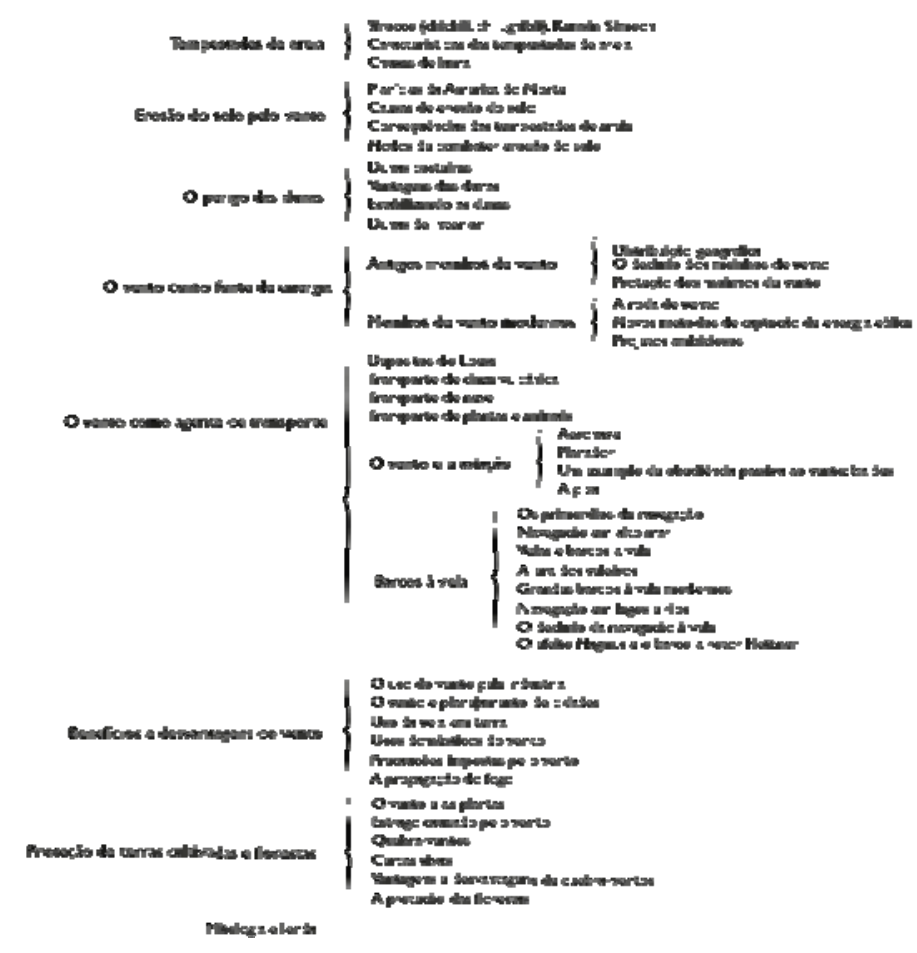

